\title{
Dijital Ortamda Sanal Para ile Gerçekleştirilen E-Spor Faaliyetlerinin TMS/TFRS Kapsamında Muhasebeleştirilmesine İlişkin Bir Yaklaşım
}

\author{
Feden $\operatorname{Koç}^{1 *}$ \\ 1* Uşak Üniversitesi, Karahallı Meslek Yüksekokulu, Büro Yönetimi ve Yönetici Asistanlığı Bölümü, Uşak, Türkiye, (ORCID: 0000-0003-4413-5188), \\ feden.koc@usak.edu.tr
}

(İlk Geliş Tarihi 8 Mart 2021 ve Kabul Tarihi 30 Mayıs 2021)

(DOI: 10.31590/ejosat.893280)

ATIF/REFERENCE: Koç, F., (2021). Dijital Ortamda Sanal Para ile Gerçekleştirilen E-Spor Faaliyetlerinin TMS/TFRS Kapsamında Muhasebeleştirilmesine İlişkin Bir Yaklaşım. Avrupa Bilim ve Teknoloji Dergisi, (25), 34-42.

Öz

Tüm dünyada teknoloji alanında yaşanan hızlı gelişmelere paralel olarak yaygınlaşan internet kullanımı, spor alanındaki müsabakalara da yeni bir boyut kazandırmıştır. Bu bağlamda elektronik spor, kısaca e-Spor olarak da nitelendirilebilen bu faaliyet katılımcıların dijital ortamda online katılımıyla gerçekleştirilen bir spor müsabakasıdır. Dünyada yoğun ilgi gören e-Spor Türkiye'de de sayıca büyük bir kullanıcı kitlesi yakalamayı başarmıştır. Ücretli e-Spor oyunlarında kullanılan ödeme seçeneklerinden birisi olarak ödemenin dijital ortamda sanal para ile gerçekleştirilmesi bu işlemlerin TMS/TFRS'ye göre kayıt altına alınmasında, Türkiye'de sanal paraya ilişkin düzenlemelerinde göz önünde bulundurulmasını zorunlu kılmaktadır. Bu bağlamda çalışmada dijital ortamda gerçekleşen e-Spor faaliyetlerinde ödemenin sanal para ile gerçekleştirilmesi durumunda, ilgili işlemlerin TMS/TFRS'ye uygun olarak maddi olmayan duran varlıklar hesap başlığı altında değerlendirilmesi konusuna açıklık getirilmesi ve ilgili işlemlerin muhasebeleştirilmesine ilişkin örnek muhasebe kayıtlarının sunulması amaçlanmıştır.

\section{An Approaches to Accounting of E-Sports Activities with Virtual Money in the Digital Environment within the Scope of TAS/TFRS}

\begin{abstract}
The use of the Internet, which has spread all over the world in parallel with the rapid developments in the field of technology, has also given a new dimension to competitions in the field of sports. In this context, this activity, which can also be referred to as electronic sports, or e-sports, is a sporting competition that takes place in the digital environment with online participation of the participants. Esports, which is attracting a lot of attention in the world, has managed to capture a large user base in Turkey as well. As one of the payment options used in paid e-sports games, payment in the digital environment with virtual money requires that these transactions be considered in the regulations regarding virtual money in Turkey when recording these transactions according to TAS / TFRS. In this context, in this study, it is aimed to clarify the subject of evaluating the related transactions under the intangible fixed assets account heading in accordance with TAS / TFRS and presenting sample accounting records for the accounting of the relevant transactions in case of payment made with virtual money in e-Sports activities realized in digital environment.
\end{abstract}

Keywords: Virtual Money, E-Sport, Digital Game, Turkey Accounting Standards/Turkey Financial Reporting Standards (TAS/TFRS), Accounting of Electronic Sports Activities.

*Sorumlu Yazar: feden.koc@usak.edu.tr 


\section{Giriş}

Günümüz bilgi çağında bilişim teknolojilerinin yaygın olarak kullanılmaya başlanması ve spor faaliyetlerinin dijital ortama taşınması ile birlikte, e-Spor faaliyetlerinin kullanıcı sayısı tüm dünyada olduğu gibi Türkiye'de de gün geçtikçe artmaktadır. Dünya çapında yaklaşık olarak yüz milyon oyuncunun aktif olarak oynadığ 1 tahmin edilen e-Spor, insan-bilgisayar etkileşimi yoluyla video oyunu yarışmalarında bireylerin veya ekiplerin mücadelelerini kapsamaktadır (Braun vd., 2016, Griffiths vd., 2003; Seo, 2016; Seo ve Jung 2016). E-Sporlar genellikle farklı ligler ve turnuvalar tarafindan koordine edilen ve genel itibariyle oyuncuların çeşitli ticari kuruluşların sponsorluğundaki takımlara ait olan profesyonel ve amatör video oyunlarına atıfta bulunmaktadır (Warr, 2014). E-Spor, bir oyuncunun avatarının ve takım tabanlı olarak, rakipleri ile mücadele etmesi ve hedefe ulaşması sürecinin sanal bir ortamda gerçekleştirilmesine dayanmaktadır. Sanal ortamda gerçekleştirilen e-Spor'da oyuncu başarı sağlamak amacıyla öngörü, sezgi, kalıp hatırlama, görsel arama davranışı ve hızlı karar verme gibi algısal ve bilişsel yetenekleri ile klavye ve fare hareketleri gibi alana özgü becerilerini birleştirme ihtiyacı duymaktadır (Pluss vd., 2019). Oyuncuların tüm bu becerilerini kullanarak dijital ortamda insan bilgisayar etkileşimi yoluyla oynadıkları bu oyunun, gerçekte bir spor olarak kabul edilip edilemeyeceği konusu ise hala tartışılmaya devam edilmektedir. E-Spor'un gerçekte bir spor olarak kabul edilmesine karşı gösterilen bu direncin nedeni, eSpor oyuncularının geleneksel spor oyuncusunun aksine oturarak oyun oynamalarından kaynaklanmaktadır. $\mathrm{Bu}$ bağlamda oyuncuların spor yeteneklerinin fiziksel becerilerinin ölçülemediğine inanılmaktadır (Taylor ve Witkowski, 2010; Witkowski, 2009; Witkowski, 2012). E-Spor'a ilişkin yukarıda sunulmuş bilgilere ek olarak, e-Spor oyunlarında ödeme ve tahsilatlar nakit, kredi kartı, mobil ödeme, kredi kartı ile entegre mobil cihazlar ve sanal para ile gerçekleştirilebilmektedir (Ankara Kalkınma Ajansı Raporu, 2016). Ödeme ve tahsilatların gerçekleştirilmesinde sanal para dışındaki seçeneklerin kullanılması bu işlemlerin takibini ve muhasebeleştirilmesini kolaylaştırmakta iken, bu oyunlarda ödeme aracı olarak sanal paranın kullanılması bu işlemlerin takibini ve muhasebeleştirilmesini de zorlaştırmaktadır. Bu bağlamda eSpor'un dijital ortamda fiziksel paraya alternatif olarak sanal para ile de gerçekleştiriliyor olması, bu faaliyetlerin TMS/TFRS'ye uygun olarak nasıl muhasebeleştirileceği konusunda sanal para kavramının da irdelenmesini gerektirmektedir.

Gerçek ve tüzel yatırımcıların olduğu kadar bazı devletlerin de ilgi gösterdiği sanal paralar, merkezi bir otoriteye bağlı olmamaları ve fiziksel bir yapıya sahip olmamaları bakımından bu paralar ile gerçekleştirilen işlemlerin takibinde şeffaflık sağlanamamaktadır. Dolayısıyla günümüz bilgi çağında sanal para birimlerinin, elektronik ortamda gerçekleştirilen ödemelerde yaygın olarak kullanılmaya başlandığı bu süreçte bazı ülkeler farklı sanal para birimlerini tanıma yoluna giderek bu konuya ilişkin yasal düzenlemelere odaklanırken, bazı ülkeler ise sanal paraya ilişkin sorunları görmezden gelmektedirler. Sanal paralara ilişkin yasal bazı düzenlemeler gerçekleştiren ve fiziksel bir yapıya dayanmayan bu paraların takibini sağlayabilmek amacıyla merkezi bir sistem arayışına giren ülkelerde ve bu paraların muhasebeleştirilmelerine ilişkin, bazı yaklaşımlar da öne sürülmektedir. Bu bağlamda Türkiye'de sanal paralara ilişkin yasal düzenlemeler T.C. Merkez Bankası, Sermaye Piyasası Kurulu ve Maliye Bakanlığı kurumları tarafından çalışılmaktadır. Türkiye'de mevcut vergi kanunları ve ticaret kanununun yanı sıra özellikle TMS/TFRS açısından yapılan değerlendirmeler neticesinde sanal paraların muhasebeleştirilmesinde sunulan öneriler 3 grupta toplanmıştır. Buna göre sanal paranın bir varlık olarak kullanım amacı belirlendikten sonra bir nakit, bir finansal yatırım aracı veya bir emtia olarak kabul edilmeleri durumunda nakit ve nakit benzeri, finansal araç veya maddi olmayan duran varlık olarak kabul edilerek muhasebe kayıtlarına alınması önerilmişti (Karaçalı, 2019). Fakat UFRS yorumlama komitesi tarafindan 21 Haziran 2019 tarihli "Holdings of Cryptocurrencies" adlı toplantısında, sanal paranın nakit ve nakit benzeri varlık ile finansal araç olarak kabul edilemeyeceğine yönelik değerlendirme yapılmıştır. Dolayısıyla bu değerlendirmeler neticesinde sanal paranın muhasebeleştirilmesinde, en uygun yaklaşım sadece dijital ortamda kullanılabilen bu paranın maddi olmayan duran varlık olarak değerlendirilmesidir.

Tablo 1'de e-Spor ve e-Spor faaliyetlerinin muhasebeleştirilmesinde esas alınan ödeme araçlarından birisi olan sanal paraya ilişkin literatürde yer alan bazı çalışmalar ve bu çalışmalardan elde edilen sonuçlar listelenmiştir.

Tablo 1. E-Spor ve Bu Faaliyetlerin TMS/TFRS'ye Uygun Olarak Muhasebeleştirilmesinde Esas Alınan Sanal Para ile İlişkili Literatürde Yer Alan Bazı Çalışmalar ve Bu Çalışmalardan Elde Edilen Sonuçlar

\begin{tabular}{|c|c|c|c|c|}
\hline Yazarlar & Yil & Çalışmanın amacı & Çalışmadan elde edilen sonuçlar & Atıf \\
\hline $\begin{array}{lr}\text { Abbas, } & \text { Basim } \\
\text { Khudhair } & \& \\
\text { Jasim, } & \text { Israa } \\
\text { Asaad \& } & \text { Nsaif, } \\
\text { Waseem Saad }\end{array}$ & 2019 & $\begin{array}{l}\text { Çalışmanın amacı dünyada } \\
\text { elektronik spor endüstrisinin ve } \\
\text { önemli elektonik spor başarılarının } \\
\text { karşılaştırmalı bir analizini } \\
\text { geçekleştirmektir. }\end{array}$ & $\begin{array}{l}\text { Günümüzde League of Legends, Counter-Strike ve } \\
\text { Overwatch gibi en popüler e-Spor oyunlarının temeli } \\
\text { beceriye dayalı rekabete dayanmaktadır. Bu oyunlar } \\
\text { belirli rollerde ustalaşanlar ve derinlemesine oyun } \\
\text { bilgisi edinenlerin ödüllendirilmesi için tasarlanmıştır. } \\
\text { Profesyonel olmayan oyuncular için çevrimiçi } \\
\text { turnuva platformlarına çok sayıda yatırım yapılmışır. }\end{array}$ & $\begin{array}{l}\text { (Abbas, vd., } \\
\text { 2019: 144-153) }\end{array}$ \\
\hline $\begin{array}{l}\text { Pluss, Matthew A. } \\
\& \text { Bennett, Kyle J. } \\
\text { M. \& Novak, } \\
\text { Andrew R. \& } \\
\text { Panchuk, Derek \& } \\
\text { Coutts, Aaron J. \& } \\
\text { Fransen, Job }\end{array}$ & 2019 & $\begin{array}{l}\text { Çalışmada elektronik sporların, } \\
\text { insan uzmanlığının geliştirilmesine } \\
\text { ilişkin bir firsat sunup sunmadığ } 1 \\
\text { değerlendirilmektedir. }\end{array}$ & $\begin{array}{l}\text { Elektronik performansta, uzman performans } \\
\text { yaklaşımını uygulamanın avantajları şunlardır; } \\
\text { (i) geliştirme faaliyetleri objektif olarak izlenir ve } \\
\text { çevrimiçi ortamda otomatik kaydedilir, (ii) temsili } \\
\text { görevlerin kısıtlamaları, e-Spor performansının } \\
\text { gerçek dünya ortamına karşılık gelir (iii) uzmanlık } \\
\text { olmadan ortaya çımıştır. }\end{array}$ & $\begin{array}{l}\text { (Pluss vd., 2019: } \\
1-5)\end{array}$ \\
\hline
\end{tabular}




\begin{tabular}{|c|c|c|c|c|}
\hline $\begin{array}{l}\text { Hallmann, Kirstin } \\
\& \text { Giel, Thomas }\end{array}$ & 2018 & $\begin{array}{l}\text { Çalışmanın amacı e-Spor'un bir spor } \\
\text { olarak kabul edilip edilemeyeceğini } \\
\text { değerlendirmektir. }\end{array}$ & $\begin{array}{l}\text { E-spor faaliyetlerini henüz bir spor olarak } \\
\text { değerlendirmek mümkün olmamakla birlikte e- } \\
\text { Spor'un bir spor haline gelme potansiyeli } \\
\text { bulunmaktadır. Çalışma kapsamında Pazarlamacıların } \\
\text { ve yöneticilerin e-Sporlara katılabilmeleri konusunda } \\
\text { farklı firsatlar özetlenmiștir. }\end{array}$ & $\begin{array}{l}\text { (Hallmann ve } \\
\text { Giel 2018: 14- } \\
\text { 20) }\end{array}$ \\
\hline $\begin{array}{l}\text { Macey, Joseph \& } \\
\text { Hamari, Juho }\end{array}$ & 2018 & $\begin{array}{l}\text { Çalışmanın amacı kumar etkinliği } \\
\text { ile video oyunlarının tüketimi ile e- } \\
\text { Spor arasındaki ilişkileri } \\
\text { araştırmaktır. }\end{array}$ & $\begin{array}{l}\text { Video oyunu bağımlılı̆̆ının çevrimiçi ve çevrimdışı } \\
\text { kumarla olumsuz bir şekilde ilişkili olduğu } \\
\text { belirlenmiştir. E-Spor tüketiminin, çevrimiçi kumar } \\
\text { ve sorunlu kumarla küçük ila orta düzeyde ilişkili } \\
\text { olduğu saptanmıştır. }\end{array}$ & $\begin{array}{lr}\text { Macey } & \text { ve } \\
\text { Hamari } & 2018: \\
344-353) & \end{array}$ \\
\hline $\begin{array}{l}\text { Hamari, Juho \& } \\
\text { Sjöblom, Max }\end{array}$ & 2017 & $\begin{array}{l}\text { Çalışmanın amacı insanları e-Spor'u } \\
\text { internette izlemeye yönlendiren } \\
\text { etmenleri belirlemektir. }\end{array}$ & $\begin{array}{l}\text { Sonuçlar, kaçış, oynanan oyunlar hakkında bilgi } \\
\text { edinme, yenilik ve e-Spor saldırganlığının e-Spor } \\
\text { izleme sıklığını etkilediğini göstermektedir. }\end{array}$ & $\begin{array}{lr}\text { (Hamari } & \text { ve } \\
\text { Sjöblom, 2017: } \\
\text { 211-232) }\end{array}$ \\
\hline Seo, Yuri & 2013 & $\begin{array}{lcr}\text { Çalışmanın } & \text { amacı } & \text { e-Spor } \\
\text { kavramının } & \text { rekabetçi } & \text { oyun } \\
\text { deneyimine } & \text { dayalı perspektifini } \\
\text { geliştirerek, e-Spor'un deneyimsel } \\
\text { değerinin nasıl ortaya çıtığını } \\
\text { irdelemektir. }\end{array}$ & $\begin{array}{l}\text { E- Spor faaliyetlerinin geliştirilmesinde ve bu } \\
\text { faaliyetlerin sürdürülmesinde oyun şirketlerinin, } \\
\text { oyuncuların, çevrimiçi toplulukları, yönetim } \\
\text { organlarının ve diğer paydaşların işbirlikleri } \\
\text { önemli rol oynamaktadır. }\end{array}$ & $\begin{array}{l}\text { (Seo, 2013: } \\
1542-1560)\end{array}$ \\
\hline $\begin{array}{l}\text { Lee, Donghun \& } \\
\text { Schoenstedt, } \\
\text { Linda J. }\end{array}$ & 2011 & 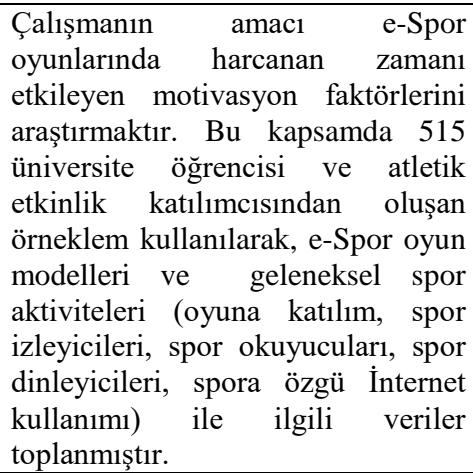 & $\begin{array}{l}\text { Hedef kitlelerin tüketim davranışlarını belirli e-Spor } \\
\text { oyunlarına yönlendiren mesajlar geliştirmek, } \\
\text { pazarlamacıları daha büyük pazar payı } \\
\text { yakalayabilmeleri } \\
\text { sağalayabilmektedir. Rekabet ve beceriye olan ilgi e- } \\
\text { Spor oyuncuları için kritik önem taşımaktadır. Bu } \\
\text { kapsamda pazarlamacılar, oyuncuların birbirleriyle } \\
\text { rekabet etmeleri için kazanana somut ödüller } \\
\text { verebilirler. Akran baskısının kullanılması oyun } \\
\text { oynamak için bir başka motivasyon faktörüdür. }\end{array}$ & $\begin{array}{ll}\text { (Lee } & \text { ve } \\
\text { Schoenstedt } & \\
\text { 2011: 39-44) }\end{array}$ \\
\hline $\begin{array}{l}\text { Pelucio-Grecco, } \\
\text { Marta Cristina \& } \\
\text { Santos Neto, } \\
\text { Jacinto Pedro dos } \\
\& \quad \text { Constancio, } \\
\text { Diego }\end{array}$ & 2020 & $\begin{array}{l}\text { IFRS'ye uygun olarak, sanal } \\
\text { paraların muhasebelestirilmesi ile } \\
\text { ilgili öneriler sunarak ve bunların } \\
\text { ana vergi yönlerini analiz etmek } \\
\text { amaçlanmıştır. }\end{array}$ & 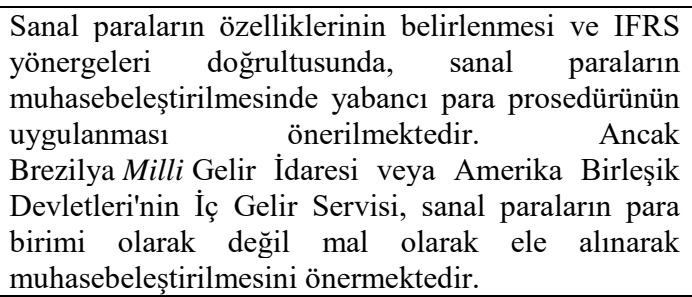 & $\begin{array}{l}\text { (Pelucio vd., } \\
\text { 2020: 275-282) }\end{array}$ \\
\hline $\begin{array}{l}\text { Stancheva, } \\
\text { Eleonora }\end{array}$ & 2019 & $\begin{array}{lr}\text { Sanal } & \text { paranın } \\
\text { muhasebeleştirilmesine } & \text { 1şık tutmak } \\
\text { amaçlanmmşır. }\end{array}$ & $\begin{array}{l}\text { Muhasebe düzenleyicileri ve standart belirleme } \\
\text { organlarının, sanal paralara ilişkin sorunları } \\
\text { benimseyerek, sanal paraların muhasebeleştirilmesini } \\
\text { şekillendirmelidirler. }\end{array}$ & $\begin{array}{l}\text { (Stancheva } \\
\text { 2019: } 1-17 \text { ) }\end{array}$ \\
\hline Procházka, David & 2018 & $\begin{array}{lr}\text { Sanal } & \text { paraların } \\
\text { muhasebeleştirilmesinde, IFRS } \\
\text { kapsamında potansiyel muhasebe } \\
\text { modellerini karşılaştırarak en uygun } \\
\text { modelin önerilmesi amaçlanmıştır. }\end{array}$ & $\begin{array}{l}\text { Gerçeğe uygun değer muhasebesi, kripto para } \\
\text { birimlerinin raporlanmasında en uygun yöntemdir. }\end{array}$ & $\begin{array}{l}\text { (Procházka, } \\
\text { 2018: 161-188) }\end{array}$ \\
\hline
\end{tabular}

Çalışma kapsamında dijital ortamda sanal para üzerinden gerçekleştirilen e-Spor faaliyetlerinin TMS/TFRS'ye uygun olarak muhasebeleştirilmesi konusunun incelenmesi ile sağlanacak katkıların bahsedilmesinde fayda vardır. $\mathrm{Bu}$ çalışmanın oluşturulması ile sağlanacak katkılar aşağıda sunulmuştur.

- $\quad$ E-Spor kavramı açıklanarak, bu faaliyetlerin genel yapısı ve unsurları incelenmiştir. E-Spor'un geleneksel spor ile farklarının da ele alındığı bu çalışmada ayrıca 2019 yılında en çok kazanç sağlayan ücretli ve ücretsiz e-Spor oyunlarına, 2020 yılında en çok ödül dağıtan ilk on eSpor oyununa ve 2020 yılında Amerika Birleşik Devletleri'nde e-Spor oyunlarından en yüksek kazanç sağlayan ilk on e-Spor oyuncusuna ilişkin bilgiler de sunulmuştur.

- E-Spor faaliyetlerine ilişkin dijital ortamda kullanılan ödeme araçlarından birisi olarak sanal paranın kullanılması halinde, TMS/TFRS'ye uygun olarak düzenlenmiş hesap planı çerçevesinde, sanal paranın maddi olmayan duran varlık olarak değerlendirilmesi durumunda bu faaliyetlerin nasıl muhasebeleştirilmesi gerektiği konusuna açıklık getirilmiştir.

Yapılan yerli ve yabancı literatür taraması neticesinde sanal para ile gerçekleştirilen e-Spor faaliyetlerinin TMS/TFRS'ye uygun olarak muhasebeleştirilmesine ilişkin herhangi bir çalışmaya rastlanmamıştır. Dolayısıyla oluşturulmuş bu çalışma 
ile dijital ortamda sanal para ile gerçekleştirilen e-Spor müsabakaları kapsamındaki işlemlerin TMS/TFRS'ye uygun olarak hangi hesap başlıkları altında sunulabileceğine ilişkin açıklamalar ve nasıl muhasebeleştirilebileceğine ilişkin örnek muhasebe kayıtları sunularak, e-Spor faaliyetlerinin, standartlara uygun olarak maddi duran varlıklar kapsamında muhasebeleştirilmesi konusuna açıklık getirilmesi ile literatürde bu alandaki boşluğun doldurulması amaçlanmıştır.

\section{E-Spor Kavramı ve E-Spor'un Genel Yapısı}

$\mathrm{Bu}$ başlık altında dijital ortamda gereçekleştirilen e-Spor faaliyetlerine ilişkin kavramsal tanımlamalar sunularak, e-Spor faaliyetlerinin genel yapısı değerlendirilmiştir.

\subsection{E-Spor Kavramı}

Günümüz bilgi çağında internet kullanımına paralel olarak sosyal ve kültürel gibi daha birçok alanda yaşanan değişimler oyun sektöründe de etkisini göstermektedir. $\mathrm{Bu}$ bağlamda oyunların dijital ortama taşınması ile birlikte karşımıza çıkan kavramlardan birisi olan ve bu çalışmanın konusunu oluşturan, insan bilgisayar etkileşimi yolu ile gerçekleştirilen e-Spor'a ilişkin literatürde birçok tanımlama bulunmakladır. $\mathrm{Bu}$ tanımlamalara katkı sağlayanlardan Wagner (2006) e-Spor'u "insanların bilgi ve iletişim teknolojilerini kullanarak zihinsel ve fiziksel yeteneklerini geliştirdikleri ve eğittikleri, spor etkilerinin yapıldığ 1 bir alandır" şeklinde tanımlamıştır. Warr (2014) eSpor'u "sporun birincil yönlerinin elektronik ortamda kolaylaştırıldığı, oyuncuların ve takımların girdilerinin yanı sıra insan-bilgisayar arayüzleri ile e-Spor sisteminin çıktısına aracılık edildiği bir spor türüdür" şeklinde tanımlamıştır. Başka bir tanımlamada Pluss vd., (2019) e-Spor'u “insan-bilgisayar etkileşimi yoluyla video oyunu yarışmalarında bireyler ve/veya oyuncu ekiplerinin rekabetçi etkileşimidir." Şeklinde tanımlamıştır.

E-Spor kavramına ilişsin yukarıda sunulmuş tanımların genel bir değerlendirmesi yapıldığında e-Spor'u, oyuncuların bireysel ve takım olarak, dijital ortamda insan-bilgisayar etkileşimi yoluyla bilişsel ve alana özgü yeteneklerini kullanarak rekabet ettikleri oyun olarak tanımlamak mümkündür.

\subsection{E-Spor'un Genel Yapısı}

E-Spor genel yapısı itibariyle takımlar, etkinlikler, oyuncular ve ligler olmak üzere 4 temel ana unsurdan oluşmaktadır. Ayrıca e-Spor oyunlarını kapsamlarına göre amatör rekabetçi oyunlar ve profesyonel rekabetçi oyunlar olmak üzere iki gruba ayrılmaktadırlar. Aşağıda Şekil 1'de dijital ortamda oynanan eSpor'un, genel yapısına ilişkin bir görsel sunulmuştur.

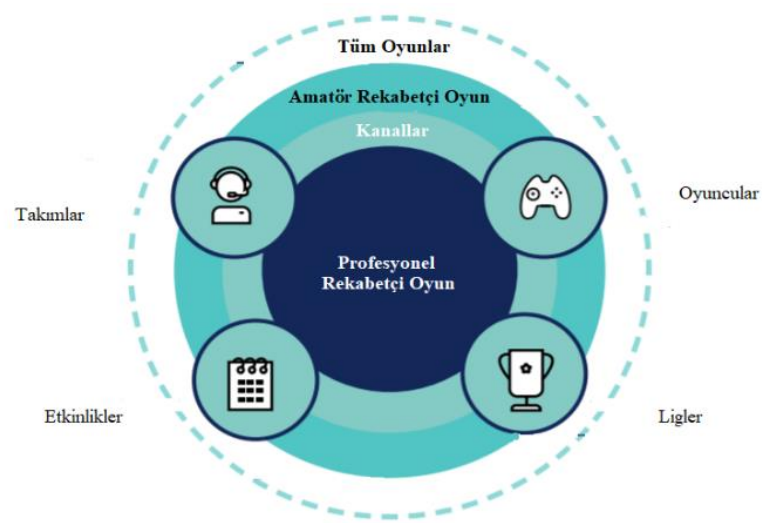

Kaynak: (Warman, 2017'den uyarlanmıştır.)

Şekil 1. Dijital Ortamda Gerçekleştirilen E-Spor'un Genel Yap1s1

Geleneksel spor ile karşılaştırıldığında e-Spor'un bir spor olarak kabul edilmediği belirli bir kesime karşın, e-Spor'un neden bir spor olarak değerlendirilmesi gerektiği, sporun ana koşulları değerlendirilerek incelenmelidir. Bir aktivitenin spor olarak kabul edilebilmesi için gerekli olan altı koşul bulunmaktadır. Bu koşullar insan, fiziksel aktivite, beceri, yarışma, kural tarafindan yönetilme ve kurumsallaşmadır. Bir aktivitenin spor olarak değerlendirilebilmesi için gerekli olan koşullar aşağıda açıklanmıştır (Parry, 2019);

İnsan: Spor insanlar tarafından gerçekleştirilen bir girişimdir. Dolayısıyla dijital ortamda gerçekleştirilen e-Spor faaliyetlerinde kontrolün insanlarda bulunması dolayısıyla, eSpor'u de bu kriter açısından spor olarak değerlendirmek mümkündür.

Fiziksel hareket: Spor, gerçek fiziksel hareketin bir sonuç üretmesi anlamında fizikseldir. Dolayısıyla e-Spor'da oyuncular gerçek bir fiziksel harekete alternatif olarak bu hareketi kendileri adına bilgisayara yaptırdıkları ve bu esnada fiziksel fikirlerini kullandıkları için e-Spor'u da bir spor olarak değerlendirmek mümkündür (Bradley, 2017; Butler, 2017)

Beceri: Tüm sporlar, insanın fiziksel becerisini kullanmasını gerektirmektedir. Dolayısıyla e-Spor da oyuncular öngörü, hızlı karar verme, bilgisayar kullanabilme gibi algısal ve bilişsel yeteneklerinin yanı sıra klavye ve fare hareketleri gibi alana özgü becerilerini kullandıkları için e-Spor'u bir spor olarak değerlendirmek mümkündür.

Yarışma: Tüm sporlar bireylerin veya takımların mücadelesi üzerine kurgulanmıştır. Dolayısıyla e-Spor oyunları da aynı temele dayandığından bu oyunları da spor olarak değerlendirmek mümkündür.

Kural tarafından yönetilme: Tüm sporlar önceden belirlenmiş bazı kurallara bağlı olarak gerçekleştirilmektedir. Dolayısıyla bu bağlamda e-Spor da dijital ortamda başlangıçta belirlenmiş kurallar tarafindan yönetildiği için spor olarak değerlendirmek mümkündür.

Kurumsallaşma: Spor, kurumsallaşmış bir yapıda, insanların fiziksel becerilerinin kurallarla yönetildiği yarışmalardır. Dolayısıyla dijital ortamda gerçekleştirilen e-spor faaliyetlerinin bir kısmının kurumsallaştırılmış bir yapıda olduğu ve bir kısmına ilişkin ise hala kurumsallaştırma çabaların devam ettiği göz önünde bulundurulduğunda e-Spor'un bu kriter 
açısından kısmen spor olarak değerlendirildiğini söylemek mümkünüdür.

E-spor'un spor olarak değerlendirilip değerlendirilemeyeceğine ilişkin yukarıda sunulmuş sporun ana koşullarının değerlendirilmesi sonucunda, e-Spor'un tamamen kurumsallaşmasına ilişkin çabaların hala devam ettiği göz önünde bulundurularak e-Spor'un bir spor olarak değerlendirilebileceğini söylemek mümkündür. Aşağıda Tablo 2'de 2019 yılında en çok kazanç sağlamış olan e-spor oyunlarının ücretli ve ücretsiz olması bakımından kategorize edilmiş bir listesi sunulmuştur.

Tablo 2. 2019 Yılında En çok Kazanç Sağlayan Ücretli ve Ücretsiz E-Spor Oyunları

\begin{tabular}{|c|c|c|c|}
\hline \multicolumn{2}{|c|}{ En Çok Kazanç Sağlayan Ücretli e-Spor Oyunları } & \multicolumn{2}{|c|}{ En Çok Kazanç Sağlayan Ücretsiz e-Spor Oyunları } \\
\hline E-Spor Oyununun İsmi & $\begin{array}{l}\text { Kazanç } \\
\text { (Milyon \$) }\end{array}$ & E-Spor Oyununun İsmi & $\begin{array}{l}\text { Kazanç (Milyar } \\
\text { \$) }\end{array}$ \\
\hline Call of Duty: Modern Warfare & 645 milyon \$ & Dungeon Fighter Online & 1,6 milyar $\$$ \\
\hline Grand Theft Auto $V$ & 595 milyon $\$$ & Honour of Kings & 1,6 milyar $\$$ \\
\hline FIFA 20 & 504 milyon $\$$ & League of Legends & 1,5 milyar $\$$ \\
\hline$N B A 2 K 19$ & 370 milyon \$ & Pokemon Go & 1,4 milyar $\$$ \\
\hline Tom Clancy's The Division 2 & 370 milyon $\$$ & Crossfire & 1,4 milyar $\$$ \\
\hline Tom Clancy's Rainbow Six: Siege & 358 milyon $\$$ & Fate/Grand Order & 1,2 milyar $\$$ \\
\hline Borderlands 3 & 329 milyon \$ & Game for Peace & 1,1 milyar $\$$ \\
\hline
\end{tabular}

Kaynak: (Kılınç, 2019)

Yukarıdaki tabloda sunulmuş verilere göre 2019 yılında en çok kazanç sağlayan ücretli e-Spor oyunun 786 milyon dolar kazanç ile FIFA 19 olduğu ve en çok kazanç sağlayan ücretsiz e-Spor oyunun1,8 milyar dolar ile Fortnite olduğu görülmektedir.

Tablo 3. 2020 Yılında En Çok Ödül Dă̆ıtan İlk On E-Spor Oyununa İlişskin Bilgiler

\begin{tabular}{l|l|l}
\hline \multicolumn{1}{c|}{ E-Spor Oyununun İsmi } & \multicolumn{1}{c}{ Dağıtılan Toplam Ödül (\$) } & \multicolumn{1}{c}{ Turnuva Sayısı } \\
\hline Dota 2 & $229.321 .216,55$ & 1471 \\
\hline Counter-Strike: Global Offensive & $107.312 .324,93$ & 5419 \\
\hline Fortnite & $99.362 .917,41$ & 673 \\
\hline League of Legends & $81.669 .988,72$ & 2482 \\
\hline StarCraft II & $34.388 .574,78$ & 6061 \\
\hline Overwatch & $26.049 .333,28$ & 743 \\
\hline Playerunknown's Battlegrounds & $24.856 .303,57$ & 304 \\
\hline Hearthstone & $24.151 .978,24$ & 902 \\
\hline Heroes of the Storm & $18.188 .482,65$ & 475 \\
\hline Arena of Valor & $15.228 .710,62$ & 51 \\
\hline Kaynak: (htps:/Www. & \\
\hline
\end{tabular}

Kaynak: (https://www.esportsearnings.com/)

Yukarıda Tablo 3'te sunulmuş veriler incelendiğinde, 2020 yılında düzenlenmiş 1471 turnuva ile en çok ödül dağıtan e-Spor oyununun Dota 2 olduğu ve bu oyun ile dağıtılan toplam ödülün 229.321.216,55 dolar olduğu görülmektedir. 2020 yılında en çok ödül dağıtan E-spor oyunları düzenlenen turnuva sayısı açısından sıralandığında ise Dota 2, E-spor oyunu dördüncü sırada yer almaktadır. Turnuva sayısı açısından ilk üç sırada ise sırasıyla StarCraft II, Counter-Strike: Global Offensive, League of Legends E-spor oyunları yer almaktadır.

Dijital ortamda sanal para ile gerçekleştirilen e-Spor faaliyetlerinin muhasebeleştirilmesinde kullanılacak usul ve esasların, geleneksel spor faaliyetleri dolayısıyla fiziksel para ile oluşan işlemlerin muhasebeleştirilmesinden çok farklı olmayacağı düşünülse de e-Spor'un dijital ortamda gerçekleştirilmesi ve ödeme/tahsilatın sanal para ile e-ISSN: 2148-2683 gerçekleştirilmesi durumunda, TMS/TFRS kapsamında sanal para kavramının da incelenmesini gerekli kılmaktadır.

\section{TMS/TFS Kapsamında Maddi Olmayan Duran Varlıklar ve Sanal Para}

Sanal para, dijitalleşme ile birlikte fiziksel paraya alternatif olarak geliştirilmiş olan hukuksal bir güvence sağlamamakla birlikte, merkezi bir mekanizma tarafindan kontrol edilemeyen, sadece internet aracılığıyla mülkiyeti el değiştirebilmesine karşın, itibari para cinsinden ifade edilemeyen para olarak tanımlanabilir. Sanal para kullanıcılara ek bir gelir sağlaması ve fiziksel paraya göre daha hızlı el değiştirebilmesi sebebiyle yaygın olarak kullanılmaktadır. İlk olarak sanal ortamda harcama yapmak 
amacıyla ortaya çıkarılmış olan sanal paranın kullanım alanı zaman içerisinde gelişim göstermiş ve günümüzde elektronik ortamda gerçekleştirilen hemen hemen tüm işlemlerde kullanılır hale gelmiştir.

Sanal paranın işlevi gerçek bir metaya dayalı fiziksel paraya benzemekle birlikte aralarında belirgin bazı farklar da bulunmaktadır. Sanal parayı fiziksel paradan ayıran farkları bu paraların itibari değeri olmayan hayali bir para olması, sanal topluluklar tarafindan kabul gören kurallara dayanması ve sunucular tarafindan otomatik olarak yaratılması olarak sıralanabilir (Guo ve Chow, 2008). Aşağıda Tablo 4'te Avrupa Merkez Bankasına ilişkin para kategorizasyonunu gösteren bir para matrisi sunulmuştur. Bu para matrisine göre sanal paralar dijital para birimi olarak değerlendirilmiştir.

Tablo 4. Avrupa Merkez Bankasına Göre Para Matrisi

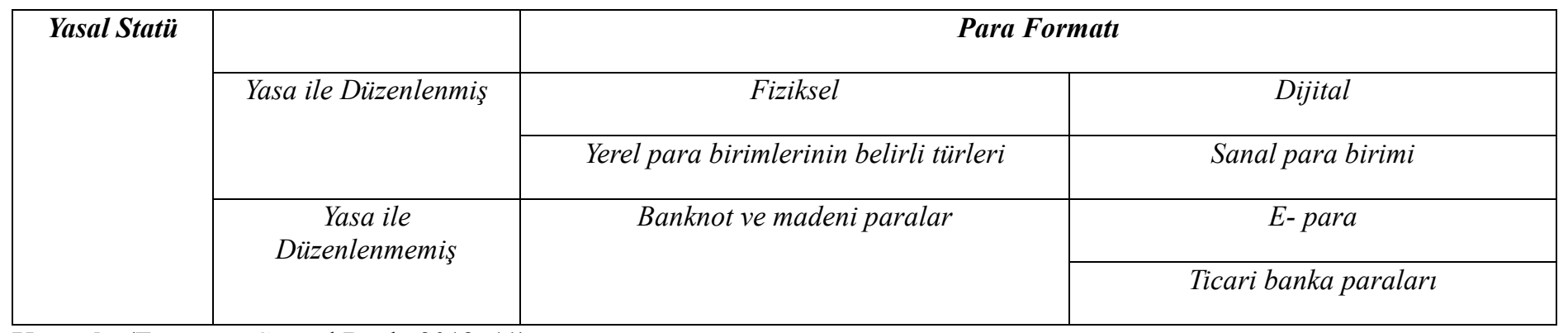

Kaynak: (European Central Bank, 2012: 11)

Sanal paranın tüm dünyada olduğu gibi Türkiye'de de yaygın olarak kullanılmaya başlanması, bu işlemlere yönelik olarak, yasal bir alt yapının oluşturulmasına duyulan ihtiyacı ortaya çıkarmıştır. $\mathrm{Bu}$ kapsamda elektronik para ile ilgili esasları düzenlemek amacıyla, 27.06.2013 tarihinde 28690 Sayılı “Ödeme ve Menkul Kiymet Mutabakat Sistemleri, Ödeme Hizmetleri ve Elektronik Para Kuruluşları Hakkında Kanun” çıkarılmıştır (Resmî Gazete, 28690 Sayılı Kanun). Ancak bu kanun kapsamında, sanal para bir elektronik para olarak değerlendirilmemiştir. Bununla birlikte Türkiye'de uygulanmakta olan muhasebe ve finansal raporlama standartları ve UFRS yorumlama komitesinin 21 Haziran 2019 tarihli "Holdings of Cryptocurrencies" adlı toplantısında alınan karar gereğince sanal paraları nakit ve nakit benzeri varlık ve finansal yatırım olarak değerlendirmek mümkün değildir. Bununla birlikte en uygun yaklaşım sanal paranın maddi olmayan varlık olarak muhasebeleştirilmesi olmakla birlikte bu konudaki değerlendirmeler halen devam etmekte ve sanal para ile gerçekleştirilen ödeme ve tahsilatların nasıl muhasebeleştirileceğine ilişkin kesin bir düzenleme bulunmamaktadır (Aslantan, 2016; Raiborn ve Sivitanides, 2015). Aşağıda öncelikle TMS/TFRS kapsamında maddi olmayan duran varlıklar incelenmiş akabinde ise dijital ortamda kullanılabilen sanal paranın maddi duran varlıklar ile ilişkisi incelenmiştir.

\subsection{TMS/TFRS Açısından Maddi Olmayan Duran Varlıkların Kapsamı}

Maddi olmayan duran varlık TMS/TFRS'de, fiziksel niteliği bulunmayan ancak tanımlanabilen duran varlıklar olarak ifade edilmiştir (KGK, Finansal Tablo Örnekleri ve Kullanım Rehberi). $\mathrm{Bu}$ standart bilgisayar yazılımı, isim hakları, patentler, telif hakları, sinema filmleri, ithalat kotaları, müşteri listeleri, müşteri ve tedarikçi ilişkileri, ipotek hizmeti sunma hakları, müşteri sadakati, pazar payı ve pazarlama hakları vb. kapsamaktadır (TMS 38 Paragraf 9). Bu tanımlama doğrultusunda bir maddi olmayan duran varlık sadece maddi olmayan duran varlık ile ilişkilendirilen, beklenilen, gelecekteki ekonomik yararların işletme için gerçekleşmesinin muhtemel olması ve maddi olmayan duran varlığın maliyetinin güvenilir şekilde ölçülebilmesi halinde muhasebeleştirilmektedir. $\mathrm{Bu}$ bağlamda TMS/TFRS'ye göre duran varlıklar hesap sınıfı içerisinde yer alan, şerefiye ve maddi olmayan duran varlıklar hesap grubunda sunulan hesap başlıkları aşağıda sunulmuştur (KGK, Finansal Raporlama Standartlarına Uygun Hesap Planı Taslağı);

- "260 Şerefiye,

- 261 Haklar,

- 262 İşletme Dışından Elde Edilmiş Diğer Maddi Olmayan

Duran Varliklar,

- 263 İşletme İçinde Oluşturulmuş Maddi Olmayan Duran

Varlıklar,

- 264 Geliștirme Maliyetleri,

- 265 Maden Kaynakları Arama ve Değerlendirme Varlıkları,

- 266 Diğer Maddi Olmayan Duran Varlıklar,

- 267 Maddi Olmayan Duran Varlıklar Değer Düşüklüğü

Karşılıkları (-),

- 268 Birikmiş Amortismanlar (-),

- 269 Verilen Avanslar".

Yukarıda sunulmuş maddi duran varlıklara ilişkin hesap başlıkları incelendiğinde, TMS/TFRS Taslak Hesap Planının sanal parayı da kapsayacak şekilde genişletilmesi ve bu doğrultuda güncellenmesine duyulan ihtiyaç açıça görülmektedir.

Maddi olmayan duran varlıkların değerlemesinde ise standartlara göre maliyet modeli veya yeniden değerleme modelinden birisi esas alınmakta olup, standartlar maddi olmayan duran varlıkların yeniden değerlenmesinde GUD ölçüsünü esas almakta ve yeniden değerlemeye ilişkin olumlu veya olumsuz fark tutarını, özkaynaklar hesap grubu altında yeniden değerleme 
fonunda raporlamaktadır. Maddi olmayan duran varlıkların teşvikli alımlarında ise GUD ölçüsü ile değerleme yapılmaktadır. Bununla birlikte standartlarda piyasa değeri ile teşvikli bedel arasındaki fark ertelenen gelir olarak raporlanmaktadır. Maddi olmayan duran varlıklara ilişkin değer düşüklüğü ise standartlarda GUD ile değerlenip gider yazılabilmektedir (Çelik, 2012; Koç, 2018).

\subsection{E-Spor'da Sanal Paranın Maddi Olmayan Duran Varlık Olarak Değerlendirilmesi ve Bu Kapsamda Önerilen Muhasebe Kayıtları}

Maddi olmayan duran varlıklar standartlarda fiziksel bir niteliğe sahip olmayan, tanımlanabilir duran varlıklar olarak ifade edilmiştir (KGK, Finansal Tablo Örnekleri ve Kullanım Rehberi). Maddi olmayan duran varlıklar standardı, maden sanayiinde veya sigortacılar tarafindan kullanılan diğer maddi olmayan duran varlıklara veya gerçekleştirilen ilk tesis maliyetleri gibi harcamalara uygulanmaktadır (TMS 38, Paragraf 7). Bu bağlamda TMS/TFRS'de maddi olmayan duran varlıklara ilişkin yapılan tanımlamada, bu varlıkların fiziksel niteliği bulunmayan tanımlanabilir varlıklar olduğu belirtilmiştir. Bu tanımlamada yer alan unsurlar sanal para ifadesini karşılamaktadır. Nitekim sanal para da fiziksel bir niteliğe sahip olmamakla birlikte tanımlanabilirdir. Dolayısıyla sanal paranın, standartlarda maddi olmayan duran varlıklara ilişsin yapılan tanımlamaya uyduğu ve sanal paranın maddi olmayan duran varlık olarak değerlendirilebileceğini söylemek mümkündür. Bu kapsamda sanal paranın maddi olmayan duran varlık olarak değerlendirildiği durumda, sanal paranın başlangıç aşamasında edinimi halinde "266 Diğer Maddi Olmayan Duran Varlıklar" hesabının borç, sanal paranın elden çıkarılması durumunda ise 266 Diğer Maddi Olmayan Duran Varlıklar" hesabının alacak kaydedilmesi önerilmektedir. Başlangıç aşamasında maliyet değeri üzerinden kaydedilen sanal para, izleyen dönemde ise maliyet değeri veya etkin bir piyasaya sahip olması bakımından yeniden değerleme yöntemi esaslarına uygun olarak kaydedilebilmektedir. Maliyet esasına göre kaydedildiği durumda sanal paranın değerinde meydana gelen değer düşüklüğü kar veya zarar tablosuna kaydedilebilir. İlgili sanal para için aktif pazarın varlığı tespit edildiği durumda, değerlemede yeniden değerleme yöntemi seçilmesi halinde, finansal tablolar dönem sonunda daha açık bilgi sağlayabilecektir (Eren vd., 2020). Aşağıda E-Spor faaliyetleri kapsamında sanal ile gerçekleştirilen işlemlerin muhasebeleştirilmesine ilişkin örnekler sunulmuştur.

Örnek 1. E-Spor sektöründe faaliyet gösteren X A.Ş. 15.01.2021 tarihinde, işletmede arayüz tasarımı ile ilgilenen personeline 42.000 TL'lik maaşını Bitcoin sanal para ile ödemiştir. Bu bilgiler doğrultusunda sanal paranın TMS/TFRS'ye uygun olarak muhasebeleştirilmesine ilişkin önerilen kayıt aşağıda sunulmuştur.

\section{$15 / 01 / 2021$}

792 Memur Ücret ve Giderler

266 Diğer Maddi Olmayan Duran Varlıklar 266.01 Bitcoin

Çalışana bitcoin sanal para ile maaş ödemesi

Örnek 2. Dijital ortamda e-Spor sektöründe faaliyet gösteren Y A.Ş. 18.01.2021 tarihinde e-Spor'da profesyonel oyuncuların yetiştirilmesine yönelik olarak işletme bünyesinde uluslararası çapta video dersler vermeye başlamıştır. Sanal ortamda işletme tarafindan verilen bu hizmetin bedeli olan 8.000 TL'yi Tether sanal para üzerinden tahsil edilmiştir (İşlemlerde KDV ihmal edilmiştir). $\mathrm{Bu}$ bilgiler doğrultusunda sanal paranın TMS/TFRS'ye uygun olarak muhasebeleştirilmesine ilişkin önerilen kayıt aşağıda sunulmuştur.

\section{$18 / 01 / 2021$}

263 İşletme İçinde Oluşturulmuş Maddi Olmayan Duran Varlıklar 263.01 Tether

601 Yurtdışı Satışlar Diğer Maddi Olmayan Duran Varlıklar 601. Hizmet Satış1

Thether sanal para ile tahsil edilen videolu ders hizmet bedeli

Örnek 3. E-Spor sektöründe faaliyet gösteren ve oyun geliştiren $\mathrm{Z}$ A.Ş. 21.01.2021 tarihinde yeni bir E-Spor oyununun tasarlanmas1 amaciyla modelleme ve render hizmetlerini, vergi mükellefi olan başka bir işletmeden sağlamış ve hizmet karşılığında 4.000 TL'lik ödemeyi Ethereum sanal para üzerinden ödemiştir (İşlemlerde KDV ihmal edilmiştir). Bu bilgiler doğrultusunda sanal paranın TMS/TFRS'ye uygun olarak muhasebeleştirilmesine ilişkin önerilen kayıt aşağıda sunulmuştur 
793 Dişarıdan Sağlanan Fayda ve Hizmetler

793.01 Modelleme ve render hizmeti

\section{2 İşletme Dişından Elde Edilmiş Diğer Maddi OlmayanYurtdışı Satışlar Diğer Maddi Olmayan \\ Duran Varlıklar \\ 266.01 Ethereum}

Ethereum sanal para ile gerçekleştirilen modelleme ve render hizmetlerine ilişkin ödeme

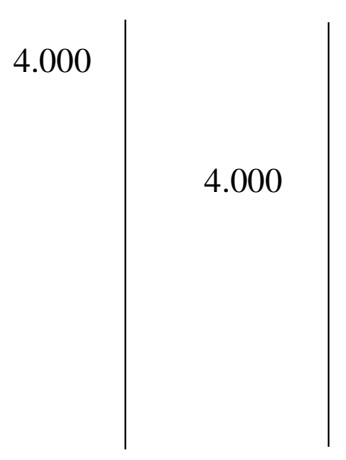

\section{Sonuç}

Günümüzde bilgi teknolojilerinin yaygın olarak kullanımı ve spor faaliyetlerine duyulan ilgiye paralel olarak gelişen e-Spor, gerçek bir spor olarak kabul edilmesine ilişkin tartışmalar halen sürmekte iken, tüm dünyada olduğu gibi Türkiye'de de oldukça büyük bir kullanıc kitlesi yakalamayı başarmışıtır. Bir oyuncunun avatarının rakipleri ile mücadele ederek hedefe ulaşması sürecini kapsayan e-Spor, dijital ortamda gerçekleşmektedir. E-Spor dijital ortamdaki insan bilgisayar etkileşimi yoluyla oyuncuların algısal ve bilişsel yetenekleri ile alana özgü becerilerini birleştirerek hedefe ulaşmalarına imkan sağlamaktadır. Oyuncular dijital ortamda gerçekleștirilen e-Spor'da ödeme aracı olarak nakit, mobil ödeme, kredi kartı, kredi kartı ile entegre mobil cihazlar ile sanal para seçeneklerinden herhangi birisini kullanabilmektedirler. Bu noktada e-Spor'da ödemenin fiziksel paraya alternatif olarak sadece internet ortamında kullanılabilen sanal para ile gerçekleştirilmesi, bu paranın merkezi bir otorite tarafindan kontrol edilememesi, kullanıcilara herhangi bir güvence sağlamaması ve kayıt dışı ekonominin oluşumuna neden olabilmesi bakımından üzerinde dikkatle durulması geren bir konudur. Türkiye'de sanal paraların takibi ve vergilendirilmesi konusunda kesin bir düzenleme bulunmamakla birlikte bu konudaki çalışmalar devam etmektedir. Bu noktada sanal para ile gerçekleştirilen işlemlerin TMS/TFRS kapsamında muhasebeleştirilebilmesine ilişkin, tartışılmaya devam eden

\section{Kaynakça}

Abbas, B. K., \& Jasim, I. A. \& Nsaif. W. S. (2019). “A Comparative Study of the Growth of Electronic Sports in the World and the Important Global E-Sports Achievements". International Journal of Computer Science and Mobile Computing 8(1):144-53.

Ankara Kalkınma Ajansı Raporu. (2016). Dijital Oyun Sektörü Raporu.

https://www.ankaraka.org.tr/archive/files/yayinlar/ankarakadijital-oyun-sektoru.pdf, ss. 9

Aslantaş, A., B. (2016). "Kripto Para Birimleri, Bitcoin ve Muhasebesi", Çankırı Karatekin Üniversitesi Sosyal Bilimler Enstitüsü Dergisi, 7(1): 349-366

Bradley, L. (2017). "Paris Open To Esports Being An Olympic Sport In 2024 Summer Games". (https://www.sporttechie.com/paris-open-esports-olympicsport-2024-summer-games/). hukuki düzenlemelerin netleşmesi gerekmektedir. Bununla birlikte UFRS yorumlama komitesinin 21 Haziran 2019 tarihli toplantısında sanal paraya ilişkin gerçekleştirdikleri değerlendirmeleri ve sanal paranın nakit ve nakit benzeri varlık ile finansal araç kapsamında değerlendirilemeyeceğine ilişkin görüşleri, tüm dünyada sanal paranın maddi ve maddi olmayan duran kapsamında ele alınmasına ilişkin yaklaşımı güçlendirmiştir. UFRS yorumlama komitesinin bu değerlendirmesi ile birlikte TMS-38 maddi olmayan duran varlıklar standardında yer alan tanımlama ve açıklamalar da, sanal paranın maddi olmayan duran varlıklar kapsamında değerlendirilebilmesine ilişkin görüşleri desteklemektedir. Dijital ortamda sanal para ile gerçekletirilen E-spor faaliyetlerinin TMS/TFRS'ye göre muhasebeleştirilmesi kapsamında hazırlanan bu çalışmada da sanal paraların maddi olmayan duran varlıklar kapsamında değerlendirilebileceği görüşü savunulmaktadır. Ancak bununla birlikte sanal paranın TMS/TFRS'ye uygun olarak maddi duran varlıklar kapsamında değerlendirilmesi ve bu kapsamda muhasebeleştirilebilmesi için, TMS-38 maddi olmayan duran varlıklar standardında sanal paraya ilişkin açıklamalar kapsamında güncellenmesi, TMS/TFRS Taslak hesap planının ve maddi duran varlıklar hesap başlığının kapsamının sanal parayı da kapsayacak şekilde genişletilmesi önerilebilir. Bu çalışmanın devamında ise sanal paraların ülke ekonomisinde ticari işlemlerde yaygın olarak kullanılmaya başlanmasının kayıtdışı ekonomiye olası etkilerinin değerlendirilmesi amaçlanmaktadır.

Braun, B., \& Stopfer, J., \& Müller, K. W., \& Beutel, M. E., \& Egloff, B., (2016). "Personality and Video Gaming: Comparing Regular Gamers, Non-Gamers, and Gaming Addicts and Differentiating Between Game Genres". Computers in Human Behavior (55): 406-412. doi: 10.1016/j.chb.2015.09.041

Butler, N., (2017). "Esports Take Big Step Towards Olympic Recognition".

(https://www.insidethegames.biz/articles/1057203/esportstake-big-step-towards-olympic-recognition).

Çelik, E., (2012), "Türkiye Finansal Raporlama Standartları (TFRS)' nın Varlıkların Değerlemesi Hususunda Getirdiği Yenilikler: Serbest Muhasebeci Mali Müşavirlerin Bilgi Düzeylerinin Tespitine Yönelik Bir Araştırma”, Çukurova Üniversitesi, Sosyal Bilimler Enstitüsü, Doktora Tezi, Adana, ss. 174. 
Eren, B. S., (2020). "Kripto Para Kavramı ve Muhasebeleştirilmesi”. İnsan ve Toplum Bilimleri Araştırmaları Dergisi, 9(2): 28.

European Central Bank. (2012). Virtual Currency Schemes. Frankfurt am Main: European Central Bank. ISBN: 978-92899-0862-7, ss. 11.

Griffiths, M. D., \& Davies, M. N. O., \& Chappell, D. (2003). "Breaking The Stereotype: The case of Online Gaming" Cyberpsychology \& Behavior: The Impact of the Internet, Multimedia and Virtual Reality on Behavior and Society. 6(1): 81-91. DOİ: 10.1089/109493103321167992.

Guo, J., \& Chow. A. (2008). "Virtual Money Systems: A Phenomenal Analysis". 10th IEEE Conference on ECommerce Technology and the Fifth IEEE Conference on Enterprise Computing, E-Commerce and E-Services. 10th IEEE Conference on E-Commerce Technology and the Fifth IEEE Conference on Enterprise Computing. Doi: 10.1109/CECandEEE.2008.91, pp. 267-272.

Hallmann, K., \& Giel, T. (2018). "ESports - Competitive Sports or Recreational Activity?" Sport Management Review 21(1):14-20. doi: 10.1016/j.smr.2017.07.011. pp. 14-20.

Hamari, J., \& Sjöblom, M., (2017). "What is eSports and why do people watch it?" Internet Research 27(2):211-32. ISSN: 1066-2243, doi: 10.1108/IntR-04-2016-0085. pp. 211-232.

https://www.esportsearnings.com/. (2021). “Top 100 Highest Earnings for United States - Esports Player Rankings : Esports (https://www.esportsearnings.com/countries/us).

IFRS, Staff Paper, Holdings of Cryptocurrencies. (https://cdn.ifrs.org/-

/media/feature/meetings/2019/june/ifric/ap12-holdings-ofcryptocurrencies.pdf).

Kamu Gözetimi Muhasebe ve Denetim Standartları Kurumu (KGK), (2019), Finansal Tablo Örnekleri ve Kullanım Rehberi.

(www.kgk.gov.tr/Portalv2Uploads/files/Duyurular/v2/Diger/ Finansal_Tablo_Ornekleri_20.5.2013.pdf).

Karaçalı, C. (2019), "Kripto paraların muhasebeleştirilmesi: bir uygulama”. Yüksek Lisans Tezi, Bartın Üniversitesi, Sosyal Bilimler Enstitüsü.

Kamu Gözetimi Muhasebe ve Denetim Standartları Kurumu (KGK), (2019), TMS 38 Maddi Olmayan Duran Varlıklar. (https://kgk.gov.tr/Portalv2Uploads/files/Duyurular/v2/TMS /TMS 2020/TMS\%2038.pdf).

Kılınç, K. (2019). “2019 Yılının En Çok Gelir Elde Eden Oyunları Açıklandı”. Webtekno. (https://www.webtekno.com/2019yilinin-en-cok-kazanan-oyunlari-h83077.html).

Koç, F., (2018), "TMS/TFRS ile Vergi Mevzuatındaki Değerleme Farklılıklarının Finansal Durum Tablosu Üzerine Etkisi: Bist'deki İşletmelerin Uygulamaları Üzerine Bir Analiz", Süleyman Demirel Üniversitesi, Sosyal Bilimler Enstitüsü, Doktora Tezi, Isparta, ss. 139-140.

Lee, D., \& Schoenstedt, L. J. (2011). "Comparison of ESports and Traditional Sports Consumption Motives". ICHPER-SD Journal of Research 6(2):39-44.

Macey, J., \& Hamari, J.(2018). "Investigating Relationships between Video Gaming, Spectating Esports, and Gambling”. Computers in Human Behavior (80):344-53. doi: 10.1016/j.chb.2017.11.027.

Parry, j. (2019). "E-sports are Not Sports". Sport, Ethics and Philosophy, ISSN: 1751-1321. 13(1):3-18. doi: 10.1080/17511321.2018.1489419.
Pelucio-Grecco, M. C., \& Santos Neto, J. P. dos, \& Constancio. D. (2020). "Accounting for Bitcoins in Light of IFRS and Tax Aspects". Revista Contabilidade \&amp; Finanças 31(83):275-82. doi: 10.1590/1808-057x201909110.

Pluss, M. A., \& Bennett, K. J. M. \& Novak, A. R., \& Panchuk, D., \& Coutts, A. J., \& Fransen. J. (2019). "Esports: The Chess of the 21st Century". Frontiers in Psychology (10):1-5. doi: 10.3389/fpsyg.2019.00156.

Procházka, D. (2018). "Accounting for Bitcoin and Other Cryptocurrencies under IFRS: A Comparison and Assessment of Competing Models". The International Journal of Digital Accounting Research (18):161-88.

Raiborn, C., \& Sivitanides, M. (2015). “Accounting Issues Related to Bitcoins". Journal of Corporate Accounting \& Finance 26(2):25-34. doi: https://doi.org/10.1002/jcaf.22016.

Resmî Gazete. Ödeme ve Menkul Klymet Mutabakat Sistemleri, Ödeme Hizmetleri ve Elektronik Para Kuruluşları Hakkında Kanun. T.C. Say1: 28690.

Seo, Y. (2013). "Electronic sports: A new marketing landscape of the experience economy". Journal of Marketing Management 29(13-14):1542-60. doi: 10.1080/0267257X.2013.822906.

Seo, Y. \& Jung S., (2016). "Beyond Solitary Play in Computer Games: The Social Practices of eSports". Journal of Consumer Culture, 16(3): 635-655. Doi: 10.1177/1469540514553711.

Stancheva, E. (2019). "Accounting for Cryptocurrencies -Some Unanswered Questions and Unresolved Issues". Sofia University, Faculty of Economics and Business Administration (19):1-17. doi: 10.13140/RG.2.2.19422.28486.

Taylor, T. L., \& Witkowski, E. (2010). "This Is How We Play It: What a Mega-LAN Can Teach Us About Games". In Proceedings of the Fifth International Conference on the Foundations of Digital Games. ACM. pp.195-202.

Wagner, M. G. On the Scientific Relevance of eSports. In Conference on Internet Computing \& Conference on Computer Games Development.

Warman, P. (2017). Global Esports Market Report. Newzoo.

Warr, P. (2014). "eSports in numbers: Five mind-blowing stats". Red Bull. (https://www.redbull.com/int-en/esports-innumbers-five-mind-blowing-stats).

Witkowski. (2009). Probing the sportiness of eSports. eSports Yearbook 2009, in Christophers, J. and Scholz, T., Books on Demand GmbH, Norderstedt.

Witkowski, E. (2012). "On the Digital Playing Field: How We 'Do Sport' With Networked Computer Games". Games and Culture 7(5):349-74. doi: 10.1177/1555412012454222. 